\title{
Właściwości urządzeń polimeryzacyjnych wykorzystywanych w stomatologii odtwórczej na podstawie przeglądu piśmiennictwa
}

\author{
Properties of polymerization devices used in conservative dentistry \\ based on a review of the literature
}

\author{
Katedra i Zakład Biomateriałów i Stomatologii Doświadczalnej \\ Uniwersytet Medyczny im. Karola Marcinkowskiego w Poznaniu
}

DOI: http://dx.doi.org/10.20883/df.2017.28

\begin{abstract}
Streszczenie
Materiały kompozytowe należą do jednych z najczęściej wykorzystywanych materiałów w bezpośredniej odbudowie zębów stałych. Materiały te od początku pojawienia się na rynku ewoluowały pod względem składu chemicznego, właściwości fizycznych, jak i samego procesu wiązania. Obecnie większość materiałów kompozytowych polimeryzuje na żądanie pod wpływem światła niebieskiego, którego źródłem są lampy polimeryzacyjne. Na rynku dostępne są różne urządzenia emitujące fale w zakresie światła widzialnego, niezbędne do inicjacji reakcji polimeryzacji. Są to lampy halogenowe, lampy ledowe, lampy plazmowe i lasery argonowe. Do urządzeń najbardziej popularnych wśród stomatologów należą dostępne od wielu lat lampy halogenowe, nowsze technologicznie lampy diodowe emitujące światło oraz mniej popularne lasery argonowe i lampy plazmowe. Różne źródła światła wiążą się nie tylko z różną technologią lamp, ale również zmienną mocą lamp, szerokością spektrum wydzielanego promieniowania, jak i dostępnymi czasami polimeryzacji. Znajomość różnic w stosowanych w codziennej praktyce lampach polimeryzacyjnych pozwala na odpowiedni wybór i stosowanie tych urządzeń w codziennej praktyce dentystycznej.
\end{abstract}

Słowa kluczowe: materiały kompozytowe, lampy polimeryzacyjne, polimeryzacja.

\begin{abstract}
Composite resins are one of the most often used dental materials in direct teeth restorations. Since their first appearance on the market they have evolved along with their chemical composition, physical properties and polymerization. Currently, most dental composites set using blue light polymerization via dental curing units. There are various devices producing the light necessary for polymerization to occur. These are quartz tungsten halogen lamps, light emitting diodes, plasma arches and argon lasers.

Having been on the market for many years the most popular and well known are quartz tungsten lamps and modern light emitting diodes; less popular are both argon lasers and plasma arches.

Different light sources mean not only different technology, but also different output power, spectral range and available pre-set times. Knowledge of these variations allows dentists to choose and successfully use dental curing lights in their everyday practice.
\end{abstract}

Keywords: composite resins, curing lights, polymerization.

\section{Wstęp}

Historia wykorzystania materiałów kompozytowych w stomatologii do odbudowy ubytków twardych tkanek zębów sięga początków lat 50. XX wieku, kiedy po raz pierwszy wprowadzono na rynek polimerowy materiał chemoutwardzalny [1]. Nieustanny rozwój $w$ tej dziedzinie, polegający między innymi na wprowadzeniu cząsteczek wypełniacza zmniejszajacego skurcz polimeryzacyjny materiału, zastąpienie żywicy metakrylanowej żywicą BIS-GMA przez Bowena [2] czy wprowadzenie cząsteczek kwarcowych silanizowanych, prowadził do uzyskiwania coraz lepszych parametrów chemicznych jak i fizycznych powyższych materiałów. Wraz ze zmianami jakościowy- mi kompozytów ewoluowały również metody ich utwardzania.

Proces polimeryzacji materiałów kompozytowych był pierwotnie inicjowany na drodze reakcji chemicznej bez udziału światła. Nazywano je wówczas materiałami chemoutwardzalnymi, utwardzanymi chemicznie lub dwuskładnikowymi [3]. Metoda ta wiązała się jednak z wieloma niedogodnościami. Dwa składniki materiału kompozytowego, bazę i katalizator, należało połączyć w odpowiednich proporcjach za pomocą szpatułki w stosunkowo krótkim czasie. Mieszanie ręczne powodowało zamykanie pęcherzyków powietrza w masie materiału, wpływając na jego wytrzyma- 
łość mechaniczną. Zmiany w proporcjach bazy i katalizatora, występujących w postaciach past lub proszku i płynu, powodowały powstawanie materiału o zaburzonym procesie polimeryzacji, który nie spełniał oczekiwanych norm chemiczno-fizycznych, co skutkowało pogarszaniem się jego jakości w odbudowie tkanek zęba.

Do dalszej popularyzacji materiałów kompozytowych przyczyniło się wprowadzenie na rynek w latach 70 . XX wieku materiałów polimeryzujących pod wpływem światła emitowanego w postaci wiązki promieniowania UV [1]. Materiały „wiązały na żądanie” lekarza dentysty, umożliwiając dokładną i etapową odbudowę zębów. Nazwano je materiałami światłoutwardzalnymi. Metoda wykorzystująca promieniowanie ultrafioletowe $\mathrm{w}$ polimeryzacji materiałów kompozytowych nie uzyskała aprobaty wśród lekarzy klinicystów i nie była długo stosowana. Obawiano się głównie o bezpieczeństwo zarówno operatorów, jak i pacjentów, zdając sobie sprawę z zagrożeń, jakie wywołują promienie UV $[4,5]$. Promienie UV zastąpiono więc światłem widzialnym, a materiały kompozytowe po niemal dwóch dekadach od pojawienia się na rynku zaczęły dominować jako podstawowy materiał w leczeniu zachowawczym zębów, służący do ostatecznej odbudowy utraconych tkanek.

\section{Urządzenia polimeryzacyjne}

Obecnie na rynku dostępnych jest kilka typów urządzeń umożliwiających polimeryzację materiatów kompozytowych za pomocą różnego rodzaju emitowanej wiązki światła. Najbardziej popularne wśród użytkowników są urządzenia z żarówkami kwarcowo-wolframowymi $z$ halogenem, zwane lampami halogenowymi (quartz tungsten halogen lamps - QTH) oraz urządzenia z diodą emitującą światło zimne (light emitting diode - LED), znane jako lampy diodowe [6, 7]. Ponadto skonstruowano urządzenia, w których wykorzystuje się wiązkę światła laserowego - lasery argonowe [8], oraz światła plazmowego - lampy plazmowe (plasma arc curing - PAC) [9], które jednak nie sprawdziły się w praktyce klinicznej.

\section{Lampy halogenowe}

Lampy halogenowe z żarówkami kwarcowo-halogenowymi były pierwszymi i są nadal dostępnymi urządzeniami na rynku, emitującymi światło widzialne. Gęstość mocy generowanego światła najczęściej waha się pomiędzy 400 a 800 mW/ $\mathrm{cm}^{2}$ [10]. Dostępne są również lampy o gęstości mocy 1500 i $3200 \mathrm{~mW} / \mathrm{cm}^{2}$ [10]. Minimalna energia dostarczana w postaci światła przez urządzenia stosowane do polimeryzacji materiałów nie po- winna nigdy wynosić mniej niż $300 \mathrm{~mW} / \mathrm{cm}^{2}$ [11]. Charakterystyczne szerokie spektrum emitowanego światła generowane przez lampy halogenowe wynika z konstrukcji lampy. Źródłem światła jest rozgrzany żarnik wolframowy, umieszczony $\mathrm{w}$ atmosferze halogenu, a cały układ jest zamknięty w kwarcowej bańce. Widmo spektralne światła emitowanego $z$ lamp halogenowych jest szerokie i wynosi w przybliżeniu od 360 do $560 \mathrm{~nm}$, a szczyt jego natężenia przypada na zakres $400-500 \mathrm{~nm}$. Tak szerokie widmo $z$ jednej strony odpowiada nie tylko materiałom kompozytowym $z$ fotoinicjatorem kamforochinonowym (CQ) [12], który pochłania promieniowanie pomiędzy 400 a $500 \mathrm{~nm}$, a maksimum jego absorpcji wynosi 470 nm [11], ale także kompozytom z innymi fotoinicjatorami. Oznacza to zgodność lamp halogenowych z większością kompozytów dostępnych na rynku.

Procedurą niepożądaną związaną z szerokim widmem promieniowania jest konieczność stosowania filtrów eliminujących zbędne $w$ procesie polimeryzacji promieniowanie podczerwone i ultrafioletowe oraz część widma światła białego. Również występowanie efektów cieplnych powoduje konieczność chłodzenia urządzenia, co wiąże się ze zwiększeniem jego rozmiarów, a tym samym zmniejszeniem poręczności. Poza tym urządzenia te bardzo mało efektywnie zamieniają energię elektryczną w światło niebieskie. Tylko 5\% uzyskanej energii to światło widzialne [13, 14]. Żywotność żarówek w lampach halogenowych jest również ograniczona i wynosi około 100 godzin [15]. Uszkodzeniom mogą również ulec system chłodzenia i filtry, a sama żarówka z upływem czasu wytwarza mniejszą moc niż nominalna, co powoduje konieczność okresowego sprawdzania parametrów lampy przy pomocy testów radiometrycznych.

Pomimo pewnych niedogodności związanych z lampami halogenowymi są one nadal często spotykanymi urządzeniami w gabinetach stomatologicznych.

\section{Lampy LED}

Lampy ledowe $z$ diodą elektroilumiscencyjną pojawiły się w pod koniec lat 90 . i wraz z rozwojem oraz popularyzacją tej technologii zyskują coraz większą popularność nie tylko w stomatologii. Wiązka promieniowania elektromagnetycznego generowana jest na skutek przepływu prądu przez półprzewodniki (dla światła niebieskiego jest to azotek galu), które w wyniku zjawiska przejścia prostego przez elektrony emitują fale elektromagnetyczne o bardzo wąskim spektrum długości fal w zakresie od 450 do $490 \mathrm{~nm}$ [16]. Dochodzi wówczas do bardzo efektywnej zamiany energii elektrycznej w światło niebieskie. 
Dla tak wąskiego spektrum, którego wartość jest bardzo zbliżona do zakresu absorpcji promieniowania przez fotoinicjator kamforochinonowy (CQ) w materiałach kompozytowych, charakterystyczny jest brak efektów cieplnych związanych z promieniowaniem podczerwonym. Wąskie spektrum światła powoduje również brak potrzeby wbudowywania filtrów zatrzymujących niepożądane promieniowanie, co ma miejsce w lampach halogenowych. Brak układu chłodzącego w postaci wentylatora w przypadku większości urządzeń dostępnych na rynku znacząco wpływa na ich rozmiar, poręczność oraz niezawodność [17]. Diody mają żywotność szacowaną na 10000 godzin [18], co w porównaniu z lampami halogenowymi (100 godzin) [15] jest wynikiem bardzo dobrym. Lampy te są także bardziej odporne na wstrząsy czy wibracje. Zasilanie urządzenia typu LED jest najczęściej bezprzewodowe, co $z$ jednej strony ułatwia prace, $z$ drugiej jednak przyczynia się do częstszego zużywania się układu zasilającego w wyniku wielokrotnych cyklów ładowania i rozładowywania baterii.

Ilość energii dostarczana na powierzchnię materiału wynosi najczęściej około $1000-1200 \mathrm{~mW} / \mathrm{cm}^{2}$ $[19,20]$. Na rynku występują również urządzenia ledowe, których moc wynosi $2000 \mathrm{~mW} / \mathrm{cm}^{2}$ a nawet $5000-6000 \mathrm{~mW} / \mathrm{cm}^{2}$. Tak duża moc przyczynia się do skrócenia czasu naświetlania, który dla standardowej lampy diodowej o mocy około 1000 $\mathrm{mW} / \mathrm{cm}^{2}$ wynosi najczęściej 20 do 40 sekund dla warstwy $2 \mathrm{~mm}$, natomiast przy lampie diodowej o mocy $2000 \mathrm{~mW} / \mathrm{cm}^{2}$ jest to 10 sekund. Dla najmocniejszych lamp czas utwardzania warstwy materiału kompozytowego skrócony jest do 3 sekund. Pomimo wąskiego spektrum światła generowanego w urządzeniach LED podczas naświetlania materiału kompozytowego obserwowany jest wzrost temperatury. Jest to spowodowane intensywnym procesem aktywacji fotoinicjatorów, egzotermiczną naturą reakcji polimeryzacji oraz energią cieplną produkowaną przez nowoczesne lampy LED o dużej gęstości mocy [21]. Standardowe lampy LED, zwane inaczej lampami monofazowymi, zawierają jeden rodzaj półprzewodnika, emitujący światło niebieskie o określonej długości fali. Polimeryzują one skutecznie materiały kompozytowe zawierające w swoim składzie fotoinicjator kamforochinonowy (CQ), natomiast nie polimeryzują efektywnie materiałów o zawartości odmiennych fotoinicjatorów. W związku z powyższym wprowadzono na rynek lampy typu polywave, które zawierają dwa lub więcej półprzewodników, emitujących światło w rożnych kolorach [22]. Oferując szersze spektrum promieniowania, wynoszące $380-520 \mathrm{~nm}$ i dwa lub więcej szczytów tego promieniowania, producent gwarantuje w ten sposób inicjację poli- meryzacji materiałów zawierających w swoim składzie takie fotoinicjatory, jak tlenek difenylo(2,4,6trimetylobenzoilo)fosfiny (TPO) [23] o maksimum absorpcji wynoszącym $380 \mathrm{~nm}$ czy acetyl benzoilu (PPD) o maksimum absorpcji $410 \mathrm{~nm}[23,24]$.

\section{Lasery argonowe i lampy plazmowe}

Kolejnymi urządzeniami polimeryzacyjnymi, które pojawiły się na rynku, są lasery argonowe oraz lampy plazmowe. Lasery argonowe są urządzeniami wyzwalającymi promieniowanie elektromagnetyczne, wykorzystującymi zjawisko emisji wymuszonej $z$ ośrodka gazowego, jakim jest argon. Produkują światło o długości fali 450-490 nm, odpowiedniej dla aktywacji fotoinicjatora kamforochinonu i prawidłowej inicjacji procesu polimeryzacji [25]. Pomimo wielu zalet związanych z wykorzystaniem lasera jako źródła światła (spójna wiązka światła o dużej penetracji materiału, mała ilość generowanego ciepła, lepszy dostęp do trudnodostępnych obszarów dzięki małym światłowodom nie odniosły one sukcesu na rynku urządzeń polimeryzacyjnych. Wpływa na to zapewne wysoki koszt zakupu urządzenia i mniejsza poręczność w porównaniu z lampami halogenowymi czy ledowymi [26]. W przypadku rozległej odbudowy, wymagającej wielu warstw, mała średnica światłowodu lasera wymusza konieczność wielokrotnego powtarzania naświetlania materiału kompozytowego [27].

Lampy plazmowe wykorzystują źródło światła w postaci łuku elektrycznego, który powstaje pomiędzy elektrodami w zamkniętej kuli ze szkła kwarcowego, wypełnionej sprężonym ksenonem oraz oparami metali. Emitują wiązkę promieniowania o długości fali w zakresie od 380 do $500 \mathrm{~nm}$. i mocy do $2500 \mathrm{~mW} / \mathrm{cm}^{2}$ [18]. Tak duża moc powoduje konieczność 10-sekundowych przerw pomiędzy kolejnymi cyklami naświetlania [28]. Obecnie zaleca się polimeryzację w cyklach trzykrotnych po 3 sekundy każdy [29]. Lampy te, podobnie jak lasery argonowe, również nie odniosły wielkiego sukcesu [17]. Są drogie, nieporęczne, a krótki czas naświetlania powoduje niewystarczającą polimeryzację niektórych rodzajów materiałów kompozytowych.

\section{Podsumowanie}

Leczenie zachowawcze zębów i związana z tym odbudowa powstałych ubytków światłoutwardzalnymi materiałami kompozytowymi jest jedną z najczęstszych procedur wykonywanych w gabinetach stomatologicznych [30]. Wraz z rozwojem materiatów kompozytowych rozwija się również rynek urządzeń służących do ich polimeryzacji. Stają się one coraz bardziej poręczne, łatwe w obsłudze i nieza- 
wodne. Producenci oferują jednocześnie lekarzowi możliwość wyboru różnych parametrów czy metod naświetlania, adekwatnych do danej sytuacji klinicznej. Lekarz stomatolog może wybierać pomiędzy lampami o różnej mocy, źródle światła i czasach naświetlania tak, aby uzyskać jak najlepsze efekty lecznicze i jakościowe. Najważniejszy jednak wydaje się dobór lampy polimeryzacyjnej, emitującej spektrum światła o zakresie najbardziej zbliżonym do zakresu absorpcji fotoinicjatorów występujących w materiałach kompozytowych. Równie ważne jest przestrzeganie zaleceń producentów dotyczących stosowania odpowiednich grubości warstw materiału kompozytowego i czasu ich naświetlania, a także okresowe sprawdzanie prawidłowej mocy lamp (szczególnie halogenowej) oraz czystości końcówek światłowodów. Wpłynie to z pewnością na uzyskanie lepszych efektów leczniczych w leczeniu zachowawczym zębów oraz satysfakcji i zadowolenia zarówno ze strony lekarza, jak i pacjenta.

\section{Oświadczenia}

\section{Oświadczenie dotyczące konfliktu interesów}

Autorzy deklarują brak konfliktu interesów w autorstwie oraz publikacji pracy.

\section{Źródła finansowania}

Autorzy deklarują brak źródeł finansowania.

\section{Piśmiennictwo}

[1] Tanasiewicz M. Stomatologia estetyczna. Kompozytowe materiały dentystyczne $w$ drodze ku nowoczesnej stomatologii. Czelej, Lublin; 2011. 78-81.

[2] Bowen RL. Composite and sealant resins - past, present, and future. Pediatr Dent. 1982;4(1):10-15.

[3] Jaskowska E, Witmanowski H. Przegląd technik utwardzania materiałów złożonych i urządzeń emitujących światło polimeryzacyjne na podstawie piśmiennictwa. Czas Stoma. 2005;4(LVIII):253-257.

[4] Małkiewicz K, Jodkowska E. Współcześnie stosowane lampy polimeryzacyjne - przegląd piśmiennictwa. Stomat Współczesna. Suplement. 2003;2:25-30.

[5] Rock WP. The use of ultra-violet radiation in dentistry. Brit Dent J 1974; 136, 455-458.

[6] Dudzik K, Iwanicka-Grzegorek E. Lampy polimeryzacyjne stosowane w stomatologii - rodzaje, zastosowanie i mechanizm polimeryzacji. Borgis - Nowa Stomatologia. 2009;4:122-127.

[7] Jung $\mathrm{H}$, Friedl $\mathrm{KH}$, Hiller KA, Furch $\mathrm{H}$, Bernhart S, Schmalz G. Polymerization efficiency of different photocuring units through ceramic discs. Oper Dent. 2006;31:68-77.

[8] Benetti A, Miranda C, de Cara-Araújo F, de Araújo M, Valera M. A Comparison of Polymerization Achieved with Argon Laser vs Soft-start and Conventional Light-curing Units. J Oral Laser Appl. 2003;3(3):141.

[9] Zahra B, Ali Asghar S, Najmeh J, Bentolhoda V. Micro-leakage of a Fissure Sealant Cured Using Quartz-tungsten-halogen and Plasma Arc Light Curing Units. J Dent Res Dent Clin Dent Prospects. 2014;8(4):252-255.

[10] Pacyk A, Wagner L. Światłem lamp stomatologicznych $\mathrm{w}$ tajemnice procesu polimeryzacji. e-Dentico. 2004;3:106-111.

[11] Caughman WF, Rueggeberg FA, Curtis JW. Clinical Guidelines for Photocuring Restorative Resins. J Am Dent Associ. 1995;126:1280-1286.
[12] Chen Y, Ferracane J, Prahl S. Quantum yield of conversion of the photoinitiator camphorquinone. Dent Mater. 2007.23:655-664.

[13] Mills RW, Uhl A, Jandt KD. depths of cure, obtained with blue light emitting diode (LED) and halogen light curing units (LCUs). Br Dent J. 2002;193:459-463.

[14] Burgess JO, Walker RS, Porche CJ, Rappold AJ. Light curing. An update. Compend Contin Educ Dent. 2002; 23:889-892, 894, 896.

[15] Thormann J, Lutz F. The type testing of light-polymerization equipment, II: 1998 status. Schweiz Monatsschr Zahnmed. 1999;109:1299-1323.

[16] Duke ES. Light-emitting diodes in composite resin polymerization. Compend Contin Educ Dent. 2001;22:722725.

[17] Broyles AC, Jack Ferracane J. Shedding Light on Curing Lights. Explore the dangers of increased temperatures and the importance of proper eye protection. IDA. 2013;10(5):34-37.

[18] Singh TK, Ataide I, Fernandes M, Lambor RT. Light Curing Devices. A Clinical Review. JOFR. 2011;1:15-19.

[19] Mousavinasab SM, Meyers I. Curing Efficacy of Light Emitting Diodes of Dental Curing Units. J Dent Res Dent Clin Dent Prospects. 2009;3(1):11-16.

[20] Pryliński S, Kleczewska J, Bociong K, Pacyk A, Domarecka $M$, Sokołowski J. Wpływ rodzaju źródła światła na efekty termiczne generowane podczas reakcji polimeryzacji kompozytu płynnego przeznaczonego do techniki „bulk fill”. Dental Forum. 2015;2(XLIII):35-41.

[21] Armellin E, Bovesecchi G, Coppa P, Pasquantonio G, Cerroni L. LED Curing Lights and Temperature Changes in Different Tooth Sites. Biomed Res Inter. 2016;1-10.

[22] Santini A, Miletic V, Swift M, Bradley M. Degree of conversion and microhardness of TPO-containing resin-based composites cured by polywave and monowave LED units. J Dent. 2012;40(7):577-584.

[23] Uhl A, Mills RW, Jandt KD. Polymerization and light induced heat of dental composites cured with LED and halogen technology. Biomaterials. 2003;24(10):1809-20.

[24] Neumann M, Schmitt C, Ferreira G, Corrêa I. The initiating radical yields and the efficiency of polymerization for various dental photoinitiators excited by different light curing units. Dent Mat. 2006;22:576-584.

[25] Khosroshahi M, Atai M, Nourbakhsh M. Photopolymerization of dental resin as restorative material using an argon laser. Lasers Med Sci. 2008;23(4):399-406.

[26] Stansbury JW. Curing dental resins and composites by photopolymerization. J Esthet Dent. 2000;12(6):300-8.

[27] Fleming MG, Maillet WA. Photopolymerization of composite resin using the argon laser. J Can Dent Assoc. 1999; 65:447-450.

[28] Albers HF. Tooth-colored restoratives principles and techniques. Resin Polymerization. BC Decker Inc. London, 2002; 81-110.

[29] Katahira N, Foxton RM, Inai N, Otsuki M, Tagami J. Comparison of PAC and QTH light sources on polymerization of resin composites. Am J Dent Assoc. 2004;17:113-117.

[30] Kopperud S, Rukke H, Kopperud H, Bruzell E. Light curing procedures - performance, knowledge level and safety awareness among dentists. J Dent. 2017;58:67-73.

Zaakceptowano do edycji: 2017-09-01 Zaakceptowano do publikacji: 2017-11-02
Adres do korespondencji:
Szymon Kubanek
Zakład Biomateriałów i Stomatologii Doświadczalnej
ul. Bukowska 70, 60-812 Poznań, pokój E417
tel.: +48793737861
e-mail: skubanek@ump.edu.pl 